\title{
Familial membranous subaortic stenosis: Review of familial inheritance patterns and a case report
}

\author{
Saulat H. Fatimi, MD, FACS, ${ }^{a}$ Usman Ahmad, MBBS, ${ }^{a}$ Muhammad A. Javed, MD, ${ }^{a}$ Sara Shamim, MBBS, ${ }^{b}$ \\ and Rizwan Ahmad, MBBS, ${ }^{\mathrm{c}}$ Karachi, Pakistan
}

Supplemental material is available online.

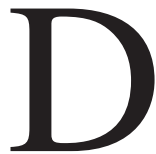
iscrete subaortic stenosis (DSS) accounts for $8 \%$ to $20 \%$ of all cases of left ventricular outflow tract (LVOT) obstruction. ${ }^{1}$ Familial incidence of DSS, although very rare, signifies the importance of screening in family members. Thus far, a clear inheritance pattern has not been reported in any single pedigree. We have described a family with 2 affected children (out of 3) and have also reviewed the inheritance patterns observed in the reported familial cases of DSS. Most cases of DSS present with systolic murmurs and with time progress to systolic dysfunction. Therefore we also explored the relationship between age and the peak LVOT pressure gradient in the familial cases.

\section{Clinical Summary}

PATIENT 1. A 3-month-old infant presented with recurrent pulmonary infections, congestive heart failure, and failure to thrive. On examination, he had a machinery murmur. Echocardiography revealed a large patent ductus arteriosus, mild pericardial effusion, severe left ventricular hypertrophy ( $\mathrm{LVH})$, moderate-to-severe subaortic stenosis, a normal aortic valve, and the presence of a subaortic membrane (Figure E1, A). The peak pressure gradient was $70 \mathrm{~mm} \mathrm{Hg}$, and the mean pressure gradient was $45 \mathrm{~mm} \mathrm{Hg}$. The child underwent surgical intervention for closure of the patent ductus arteriosus during the same admission and an elective operation for subaortic membrane removal at the age of 21 months. The subaortic membrane, surrounding hypertrophied muscles, and free wall were excised. Histopathology showed fibromuscular tissue fragments exhibiting secondary regenerative changes on a myxoid background. A follow-up echocardiogram showed moderate LVH, a peak pressure gradient of $51 \mathrm{~mm} \mathrm{Hg}$, and a mean pressure gradient of $32 \mathrm{~mm} \mathrm{Hg}$.

\footnotetext{
From the Department of Surgery, Division of Cardiothoracic Surgery, ${ }^{\mathrm{a}}$ Aga Khan University; Dow Medical College, Dow University of Health Sciences $^{\text {b; }}$ and Baqai Medical College, Baqai University of Health Sciences, ${ }^{\mathrm{c}}$ Karachi, Pakistan.

Received for publication Aug 9, 2006; accepted for publication Aug 28, 2006.

Address for reprints: Usman Ahmad, MBBS, Department of Surgery, Division of Cardiothoracic Surgery, Aga Khan University Hospital, Stadium Rd, 74800 Karachi, Pakistan (E-mail: usman.ahmad@aku.edu).

J Thorac Cardiovasc Surg 2006;132:1484-6

$0022-5223 / \$ 32.00$

Copyright $\odot 2006$ by The American Association for Thoracic Surgery doi:10.1016/j.jtcvs.2006.08.034
}

PATIENT 2. A 5-year-old, otherwise healthy sister of the proband was found to have a heart murmur. Echocardiography showed the presence of a subaortic membrane (Figure E1, B), moderate aortic stenosis, and moderate LVH. The LVOT pressure gradient was $90 \mathrm{~mm} \mathrm{Hg}$, and the mean pressure gradient was $55 \mathrm{~mm} \mathrm{Hg}$. She underwent elective surgical excision of the subaortic membrane, hypertrophied muscles, and free wall. Histopathology revealed fibromuscular tissue showing spindle-shaped cells with abundant intercellular connective tissue stroma. Postoperative echocardiography showed moderate aortic valvular stenosis and a peak pressure gradient of $72 \mathrm{~mm} \mathrm{Hg}$.

\section{Review of Cases}

A literature search yielded 5 reports ${ }^{2-5, \mathrm{E} 1}$ of 8 families in which DSS was the common anomaly in all affected members. From the information provided in the published reports, we drew pedigrees (Figure 1). ${ }^{4, \mathrm{E} 1}$ The data on age, sex, and LVOT pressure gradient were pooled and analyzed.

In most families the patients belonged to the same generation, making the interpretation of inheritance pattern difficult. Fifty-nine percent of the affected patients were male (13 vs 9). The age of presentation/operation ranged from 3 months to 30 years. No clear pattern of autosomal, X-linked, or mitochondrial inheritance was observed. Only 2 families other than our reported family had consanguineous marriages. Analysis of cases (including ours) in which information about both age and LVOT pressure gradient was present revealed a strong effect of age on the pressure gradient $\left(r^{2}=0.22, P=.037, \beta=.5,95 \%\right.$ confidence interval $\left.=0.3-9\right)$. This effect was independent of sex.

\section{Discussion}

Subaortic membranous stenosis is almost never seen at birth; however, familial occurrence suggests a genetic basis. Subaortic membrane in familial cases has been reported both as an isolated anomaly, and along with the presence of other abnormalities, some of which were congenital.

Review of pedigrees and the information provided in the published reports does not reveal a clear inheritance pattern. Large proportions of affected offspring in some families suggest a dominant character of the disease-causing allele. The absence of affected parents in such cases could be due to incomplete penetrance. Locus heterogeneity and polygenic inheritance cannot be ruled out based on these data. A complex pathologic basis with a strong role of environment (hemodynamic factors) has also been proposed. The fact that $70 \%$ of cases had been given diagnoses by the age of 10 years favors a stronger genetic basis. Almost equal proportions of affected male and female patients make X-linked inheritance 

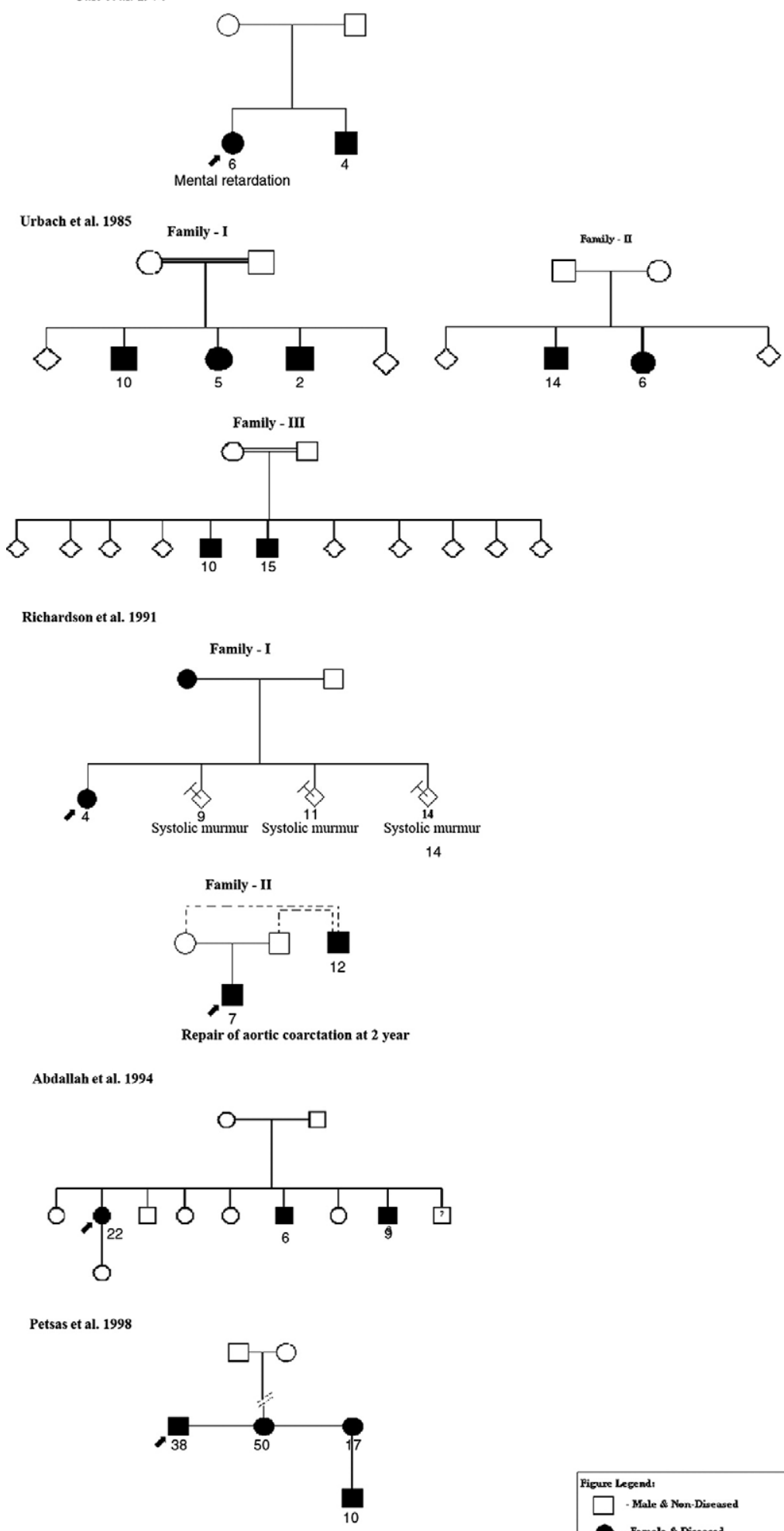

Pakistani Family
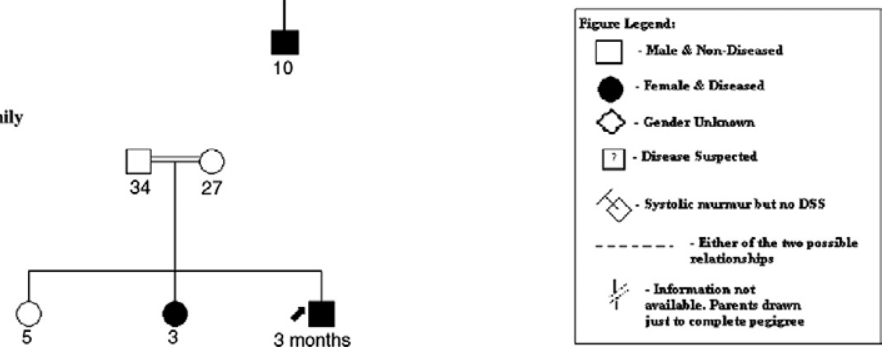

Figure 1. Pedigrees of the familial cases of discrete subaortic stenosis based on information provided in the respective published articles. Richardson and colleagues, Family $I^{4}$ : The affected male subject in the first generation is either a paternal or a maternal uncle (dashed line). Petsas and associates ${ }^{\mathrm{E}}$ : No information about the parents was available. The first generation has been drawn just to complete the pedigree. 
unlikely. Most reported pedigrees could fit into autosomal dominant or recessive inheritance with variable and incomplete penetrance. Inheritance of DSS in dogs suggests either polygenic or autosomal dominant inheritance with modifiers. ${ }^{\text {E2 }}$ Follow-up of siblings and offspring of patients in large pedigrees might help in revealing the underlying inheritance pattern.

We used the LVOT peak pressure gradient as a surrogate marker for the degree of subaortic stenosis. Age, independent of sex, was found to be a significant predictor of peak pressure. This is first time that any such relationship is being reported. This emphasizes the fact that screening for cardiac murmurs and their timely echocardiographic evaluation can lead to early diagnosis of a majority of cases of DSS. Although the exact mode of inheritance of subaortic membranous stenosis is not clear yet, documented familial clustering implies that at least the first-degree relatives of every patient with DSS and those with systolic murmurs should be evaluated for subclinical disease.

\section{References}

1. Friedman WF. Discrete subaortic stenosis. In: Braunwald E, editor Heart disease. A textbook of cardiovascular medicine. $4^{\text {th }}$ ed. Philadelphia: W. B. Saunders Co; 1992. p. 925-6.

2. Gale AW, Cartmill TB, Bernstein L. Familial subaortic membranous stenosis. Aust N Z J Med. 1974;4:576-81.

3. Urbach J, Glaser J, Balkin J, Rosenmann D, Levy R, Marin G, et al Familial membranous subaortic stenosis. Cardiology. 1985;72:214-7.

4. Richardson ME, Menahem S, Wilkinson JL. Familial fixed subaortic stenosis. Int J Cardiol. 1991;30:351-3.

5. Abdallah H, Toomey K, O'Riordan AC, Davidson A, Marks LA Familial occurrence of discrete subaortic membrane. Pediatr Cardiol. 1994:15:198-200 


\section{E References}

E1. Petsas AA, Anastassiades LC, Constantinou EC, Antonopoulos AG. Familial discrete subaortic stenosis. Clin Cardiol. 1998;21:63-5.

E2. Pyle RL, Patterson DF, Chacko S. The genetics and pathology of discrete subaortic stenosis in the Newfoundland dog. Am Heart $J$. 1976;92:324-34.

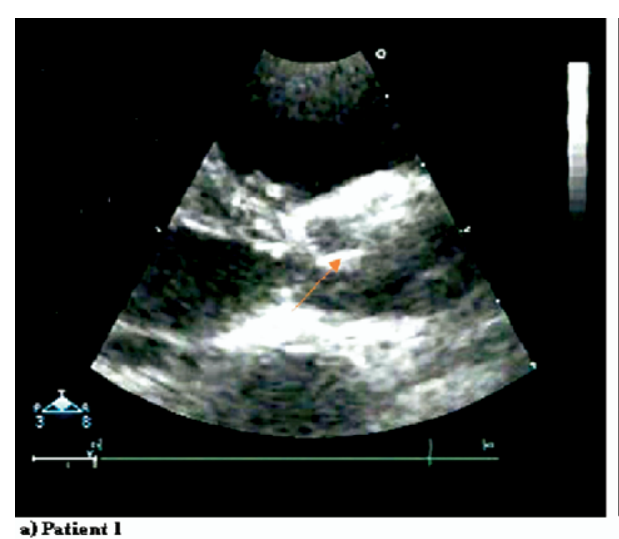

a) Patient 1

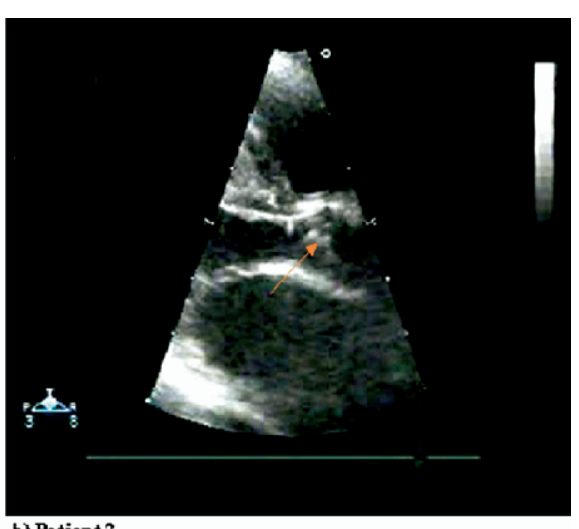

b) Patient 2

Figure E1. Preoperative echocardiograms of the patients. A, Parasternal long-axis view of patient 1. Arrow indicates the subaortic membrane, which is approximately $1.4 \mathrm{~mm}$ thick. B, Parasternal long-axis view of patient 2. Arrow indicates the subaortic membrane, which is approximately $\mathbf{2} \mathrm{mm}$ thick. 